\title{
Educação patrimonial em arquivos on-line: narrativas em rede e seus tecidos ${ }^{*}$
}

\author{
Heritage education in online archives: \\ narratives in network and their weavings
}

\author{
Adriana Carvalho Koyama \\ Historiadora e doutoranda pela Faculdade de Educação (FE-Unicamp) \\ ackoyama@mandic.com.br
}

\section{Resumo:}

Procurei refletir sobre como os arquivos têm proposto experiências educativas on-line, destacando algumas questóes fundamentais para a educação patrimonial e para o ensino de história, como a da consideração da especificidade dos documentos de arquivo, $\mathrm{e}$ que se colocam como campo de reflexão e de ação nesses novos espaços virtuais de ensino de história. Como horizonte, busco possibilidades de criação de projetos de educação com o uso de documentos de arquivo que se abram para as múltiplas dimensóes da experiência histórica e em contraposição à monumentalização dos documentos perceptível em muitos projetos educativos on-line.

Palavras-chave: Arquivos; Educação Patrimonial; Memória

\section{Abstract:}

This essay outlines how Archives have been proposing educational experiences online, highlighting some questions, such as the nature of archival records, which arise as key issues and as fields of reflection and action in these new virtual spaces of history teaching. As perspective, it looks for educational projects opened to the multiple dimensions of historical experience, and in contrast to the monumentalization of the archival records, perceptible in many of the educational projects online nowadays.

Keywords: Archives; Heritage Education; Memory

* Trabalho apresentado no GT Memória e Arquivos 
Eu me pergunto como se recordam aqueles que não filmam, que não fotografam, que não gravam vídeos, como fazia a humanidade para se lembrar...

Chris Marker, Sans Soleil. Argos-Films 1982

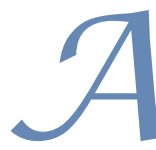

aproximação entre os temas MemóriaeArquivos nutre umcampode reflexôes contemporâneo e pleno de questóes candentes, vinculadas às pesquisas sobre arquivo, memória, patrimônio documental e ensino de história. As iniciativas de preservação do patrimônio documental têm se multiplicado, em especial desde a década de 1980, muitas vezes ligadas à afirmação de identidades: as tensóes entre preservar o que temos e somos e consumir, descartando o velho e os resíduos do novo, entre a crescente expansão urbana e a vontade de conservação, estão presentes nos movimentos daqueles que procuram valorizar as narrativas da memória e da história local hoje. Entre os pesquisadores que refletem sobre o tema estão Manuel Castells, Pierre Nora e Andréas Huyssen. Para Castells, nesse mundo de fluxos globais de riqueza, poder e imagens, a busca pela identidade, coletiva ou individual, atribuída ou construída, está-se tornando uma fonte básica de significado social. Em suas palavras,

a identidade está se tornando a principal e, às vezes, única fonte de significado em um período histórico caracterizado pela ampla desestruturação das organizaçóes, deslegitimação das instituiçôes, enfraquecimento de importantes movimentos sociais e expressóes culturais efêmeras (CASTELLS, 1999: 23).

Pierre Nora também reflete sobre as conexóes entre o alargamento do campo da memória e os arquivos. Em 2003, na Revista Comma, do International Council on Archives, o autor reflete sobre como os arquivos passaram, nas últimas décadas, de "lixo" a santuário das sociedades contemporâneas, e com eles os arquivistas, que de "démobilisé de l'histoire" ("desmobilizados da história") se alçaram a atores sociais plenos. Para Nora, o arquivo está se colocando no coração da memória contemporânea e representa sua imagem material e visível. E com a memória ele compartilha suas características de tornar-se imperativo, hipertrófico e passional.

Imperativo, pois vivemos uma ansiedade da perda, em razão do que tem sido chamado de aceleração da história, da obsolescência cada vez mais rápida de todas as coisas. Nas palavras de Nora,

Atualmente, em um mundo de evolução cada vez mais rápida, onde tudo passa tão depressa que cada acontecimento se reveste de um caráter histórico e já obsoleto, é evidente que o imperativo da memória - longe de designar apenas a dívida moral da lembrança - diz respeito mais fundamentalmente à ansiedade da perda. (NORA, 2003: 47). [Tradução da autora]

Nesse mundo em que as perdas não cessam de se alargar, de se aprofundar 
e de se generalizar, o arquivo muda de estatuto, descentraliza-se e dilata-se para receber "tudo o que pareça merecer ser lembrado", num movimento de hipertrofia. Multiplicam-se os lugares da memória e as demandas pela preservação documental (NORA, 2003).

Como descreve Andréas Huyssen (HUYSSEN, 2000) em Seduzidos pela Memória, vivemos o paradoxo de tudo destruir, de tornarmos obsoleto o próprio presente e de, ao mesmo tempo, buscarmos formas de documentar tudo, guardar tudo, preservar tudo, e de nos voltarmos para imagens de um "passado", de uma "memória" que chega quase até o presente. Sua reflexão aponta como os objetos obsoletos de ontem são colecionáveis, em uma comercialização em massa da nostalgia, com o crescimento de uma literatura memorialística, de "documentários" históricos e de eventos de comemoraçáo do passado, como se o objetivo fosse conseguir a recordação total: a memória tornou-se uma obsessão cultural de proporçôes monumentais em todos os pontos do planeta. A hipótese de Huyssen é de que algumas das facetas desse processo precisam ser percebidas através de suas ligações com as mídias. A expansão dos registros sobre o passado, ampliada pela mídia, faz "a memória" ficar aparentemente cada dia mais disponível para nós, e a publicação de documentos on-line, e sua demanda, entram no circuito de produção e consumo da memória midiatizada, que também cai em esquecimento rapidamente. Nas palavras de Huyssen, o passado está vendendo mais do que o futuro.

As mídias da informação que se projetam através da comercialização do passado são grandes consumidores da "novidade" histórica, constantemente em busca da nova imagem, de uma "descoberta" pontual para a comemoraçáo do passado. O conteúdo de suas publicaçóes, muitas vezes, lembra os das antigas revistas dos Institutos Históricos e Geográficos, em versóes midiatizadas e com sua linguagem atualizada: apologias do "progresso" e suas glórias passadas e presentes, dos "homens bons", da guerra, de documentos monumentalizados, todos com uma aura de novidade e descoberta, atração e intelectualidade.

Muitos arquivos têm participado, nessa "economia da memória", como co-produtores de imagens do passado, que circulam nas mídias como "memórias" para consumo. As demandas por documentos digitalizados dos arquivos, hoje, vêm em parte dessa circulaçáo midiática de imagens do passado para consumo e fruição. Mas seria esse o lugar social dos arquivos?

Pierre Nora, no artigo citado de 2003, descreveu essa febre arquivísitica e sua visibilidade na mídia, ao mesmo tempo em que apontou também para o aparente paradoxo de que a pesquisa documental nos arquivos continua escassa, o que é bastante compreensível: o tempo do arquivo e da pesquisa documental não é o mesmo tempo da "economia da memória" midiatizada.

Nessa nova visibilidade que vêm ganhando os arquivos, a digitalização de seus documentos, vista como possibilidade de democratização de acesso, vem ganhando espaço, investimentos e muitas novas experiências ao longo dos últimos anos. Alguns, como o National Archives and Records Administration, dos Estados Unidos, mantêm inclusive espaços nas redes sociais, como o Facebook. A publicação e o acesso on-line aos documentos de arquivo tem se tornado objeto de investimentos intelectuais, afetivos e, sobretudo, financeiros nos últimos anos, e quanto mais se expandem sua presença, seu interesse e as ferramentas tecnológicas para sua realização, menos evidentes se tornam algumas distinções fundamentais sobre 'do que se trata', por que e para quem se publica. 
Embora "a história" e "a memória" não se encontrem nos arquivos esperando para serem digitalizadas e entregues à fruição dos navegadores da rede, às vezes parece ser essa a imagem social que vem sendo criada em relação aos arquivos. Vicki Sand, que foi coordenadora da divisão de ação educativa da Minnesota Historical Society, e hoje é diretora do Philadelphia History Museum, em um artigo de 1978 para a revista American Archivist, escreveu que "Filosoficamente, os americanos escolheram guardar suas histórias nas Instituições. Em outras sociedades as pessoas levam suas histórias consigo.” (SAND, 1978: 163). [Tradução da autora] A afirmação de que as histórias do povo americano estão nos arquivos é reveladora da confusa simbiose entre arquivo e memória que vem se tecendo ao longo das últimas décadas em textos que relacionam identidade e preservação documental.

O desenvolvimento da vontade de tudo preservar é concomitante à ampliação da própria noção de documento. Mas afinal, de que concepção de documento se está falando? A concepção de documento de arquivo tem suas especificidades. "Documento", como concebe a História Nova (LE GOFF, 1984) e "documento de arquivo", com seu caráter jurídico, probatório, tal como o vêem e preservam os arquivos públicos, têm diferenças que merecem nossa reflexão. Salientamos, com Ana Maria de Almeida Camargo, a marca fundamental dos documentos de arquivo, a qualidade especular que os distingue dos demais e que permite reconhecer o acontecimento ou a ação de que são correlatos:

É preciso levar em conta - e com isso voltamos aos conceitos de base - o próprio estatuto do arquivo como conjunto articulado de documentos que se acumulam, de forma natural e necessária, em razão do funcionamento de um organismo qualquer. Os fins práticos (de natureza administrativa ou jurídica) dessa acumulação contemplam os diversos estágios por que passam os documentos, de modo a viabilizar a própria existência da instituiçáo a curto, médio e longo prazos. E é justamente por seu papel instrumental em relação à instituição de origem que o arquivo constitui um espelho fiel de suas diferentes atividades ao longo do tempo, espelho capaz de refletir - com maior ou menor intensidade e nitidez, dependendo do grau de sua intervençáo no corpo social - as realidades que a envolveram direta e indiretamente. A importância dessa matéria prima para o historiador é, sem dúvida, muito grande. (CAMARGO, 2001: 10)

Essa especificidade dos documentos de arquivo é bem conhecida dos arquivos públicos. No entanto, nem sempre é clara para os usuários, como aponta o texto "O arquivo em um mundo em transformação", do site do Arquivo da Cidade do Rio de Janeiro,

Embora os avanços tecnológicos tenham favorecido a obtenção da informação no chamado tempo real, ela não é acessível a todos e nem sempre provém de fonte confiável. Neste contexto, abundam os "arquivos" criados sem nenhum critério, os dados forjados ou obtidos 
aleatoriamente e que circulam com ares de veracidade pelos meios de comunicação[1].

Essa questão também se coloca entre os historiadores, como aponta Camargo:

À nítida tendência dos historiadores de ver os documentos de arquivo como entidades discretas, que têm vida independente e autônoma, contrapóe-se a que preconiza vê-los como partes de um conjunto, como elementos que mantêm relação orgânica entre si. Maior que a soma das partes que o integram, esse organismo é que lhes empresta autenticidade. Nesse sentido é possível dizer que os documentos carregam consigo, obrigatoriamente, a cunha da instituição que os produziu. Nenhum deles, com efeito, pode ser compreendido ou interpretado sem que se conheçam as razóes por que foi produzido ou as condiçóes de que se originou. E a resposta a tais questóes encontra-se fora do conteúdo específico dos documentos, num patamar em que predominam informaçôes não verbais: nos demais documentos da mesma série, na disposição dos documentos no âmbito de um processo, no conjunto dos documentos de um arquivo (CAMARGO, 2001: 9).

Se socialmente essas distinções não são claras, é de se imaginar que povoem, também, as relaçóes entre arquivos e escolas. Para tentar enfrentar a questão da descontextualizaçáo dos documentos no âmbito das açóes educativas dos arquivos, algumas iniciativas de pesquisadores de ensino de história, em colaboração com profissionais de arquivo, tentam lançar luz sobre a especificidade dos documentos de arquivo, por exemplo, selecionando séries documentais para serem exploradas, e náo documentos avulsos. Nesse sentido podemos apontar a experiência de Ivo Mattozzi (MATTOZZI, 2001) chamada de "arquivos simulados", entre outros.

Mas encontramos muitas propostas educativas de arquivos on-line em que os documentos se encontram descontextualizados, muitas vezes inclusive sem a identificação de seu contexto de produção.

A guarda pelos arquivos públicos dos documentos produzidos por instituiçóes e pessoas, com a aplicação dos princípios de "respeito aos fundos", de preservação de sua organicidade e caráter de conjunto, construído nas atividades cotidianas desses produtores, empresta a esses fundos documentais sua especificidade, em contraponto à forma de seleção e agrupamento intencional e descontextualizado das coleçóes de peças únicas monumentais, tâo caras às sociedades históricas e aos colecionadores de relíquias do século XIX (CHOAY, 2001). Descontextualização e monumentalizaçáo que, no entanto, seguem renovadas nas exposiçóes dos arquivos nos séculos XX e XXI, inclusive as colocadas on-line.

Essas ligações entre as coleçôes, e suas exposições, em que os documentos formam parte das narrativas, podem ser analisadas a partir de discussóes museológicas contemporâneas sobre regimes de visualidade e educação do olhar. Paulo
1 - http://www0.rio.rj.gov. br/arquivo/o-arquivo-transformacao.html Acesso em 15 de abril de 2012. 
2 - http://www.gov.ns.ca/ nsarm/virtual/newspapers/Acesso em 15 de abril de 2012.
Knauss (KNAUSS, 2003) relaciona as práticas de colecionar com práticas de exposição, salientando que o colecionismo não é demarcado apenas por regimes de acumulaçáo, ordenamento e guarda, mas, igualmente, por regimes de visualidade. Em sua reflexão sobre as coleçôes, ele coloca em questáo os usos da imagem e as bases da educação do olhar. Podemos refletir com Knauss, a partir dos documentos de arquivo publicados on-line: ao se recortarem os acervos dos arquivos e em suas seleçôes, estas se formam como coleçôes de imagens de documentos, e, no processo de se exporem nos museus virtuais, os registros custodiados pelos arquivos talvez se afirmem como documentos, e institucionalizem-se através da operação do olhar? Os "tesouros" dos arquivos nacionais, os "documentos da Nação", colocados on-line nos sites, organizam-se a partir dessa lógica das exposiçôes, espetáculos da Nação.

Ao navegarmos pelas séries documentais nos sites dos arquivos nem sempre fica claro, em especial para os que conhecem pouco os arquivos, que são seleções de documentos que estão publicadas, e não todo o acervo, ou seja, sempre é feita uma escolha e um recorte de seçóes, séries ou documentos avulsos, para expor on-line. E entre os que forem colocados on-line, os mecanismos de busca internos fazem novos recortes a partir das palavras-chave e/ou dos chamados metadados, que são descritores ligados a cada objeto digital. Essa seleção e tratamento são decisivos na experiência de ensino possibilitada na interação com o navegante-leitor. Insidiosamente, velhos problemas transportam-se para novas roupagens.

O caráter probatório dos documentos dos Arquivos Públicos para a administração talvez também contribua para fortalecer a aura de objetividade total e/ ou de evidência sobre o passado construída em torno de todos os papéis guardados nos arquivos. Essa aura é bastante perceptível, como nessa apresentação de uma coleção de primeiras páginas de jornais digitalizadas pelo Nova Scotia Archives \& Records Management, no Canadá:

Jornais são, e sempre foram, um espelho que reflete quem somos, como nossas comunidades se constituem, como vivemos nossa vida cotidiana e a maneira como vemos o mundo em que vivemos. Jornais "velhos" têm um valor especial, porque nos permitem olhar para trás e ver como o mundo era há 20,50, 100 ou até 200 anos atrás. Nova Scotia Archives \& Records Management[2] [Tradução da autora]

A ideia de que os jornais, tratados como documentos monumentalizados, sejam "espelhos" "das comunidades", de que encontremos neles "a maneira como vemos o mundo em que vivemos", se nos parece ingênua, assim colocada, está presente em muitos dos exercícios propostos com documentos on-line em sites de arquivos.

Em muitos dos escritos dos arquivistas estudados, a ampliação do espaço social dos arquivos é defendida como forma de propaganda institucional, aproximação visível, em especial em muitos dos textos ingleses, americanos e canadenses. Em busca de verbas que garantam a sobrevivência dos arquivos e a preservação de seus acervos, as exposiçóes têm intenção de dar visibilidade ao patrimônio. No entanto, ao se apropriarem dos discursos sobre "a memória social que os arquivos guardam”, essas açóes, muitas vezes, também alimentam a fantasmagoria 
de que nos arquivos está guardada toda a história e a memória.

A aproximação entre arquivos e escolas também partiu de um movimento de renovaçáo no ensino de história. Uma discussáo muito presente entre os pesquisadores de ensino de história e professores, a pesquisa histórico-escolar com o uso de documentos emergiu na década de oitenta como um dos eixos das propostas de mudança do ensino de história no Brasil. Foram publicadas diversas coletâneas de documentos para uso em sala de aula, no bojo das propostas de mudanças no ensino de história, como a da CENP-SP, de 1986, em que os alunos eram estimulados a produzir conhecimento histórico a partir da pesquisa de fontes documentais. Propostas próximas às de educadores europeus e norte-americanos daquele período.

$\mathrm{Na}$ década de noventa a busca de formas de trabalho com documentos em sala de aula se ampliou e ganhou novos contornos, com a leitura de documentos proposta nos Parâmetros Curriculares Nacionais ( $\mathrm{PCN}$ ) como experiência de aprendizagem possível e desejável para todas as fases do ensino fundamental, marcadamente como ferramenta para aquisição de habilidades de pesquisa. Os PCNs aproximam-se das propostas das reformas curriculares européias, americanas e canadenses dos anos noventa, que também recomendam fortemente o uso de documentos em sala de aula para o ensino de história desde as séries iniciais.

Essa ênfase das políticas públicas no ensino de habilidades de pesquisa para o ensino de história no ensino fundamental mantém-se até a atualidade, embora ultimamente tenha sido muitas vezes compreendida como ferramenta cognitiva, mais do que como possibilidade de produção de conhecimento histórico-escolar, como era fundamentalmente pensada nas reflexôes dos pesquisadores dos anos oitenta. Podemos reconhecer experiências parecidas nas propostas educativas on-line dos arquivos nacionais de Inglaterra e dos Estados Unidos, por exemplo. Ainda nessa direçáo, lembramos, com Galzerani, que

Os Parâmetros Curriculares de História para o ensino fundamental e médio, produzidos pelo MEC também nos anos 1990, ratificam as potencialidades do conceito de memória para o ensino de História, nestes níveis de escolarização. Contudo, em suas tessituras discursivas muitas vezes contraditórias - prevalecem os saberes de cunho científico, capazes de assegurar a (re) produção dos "parâmetros" cognitivos, ou seja, das balizas culturais, tendencialmente, homogeneizadoras, necessárias à constituição de "cidadãos", concebidos - ainda - como economicamente ativos e politicamente dóceis. (GALZERANI, 2008: 24)

Encontramos outros agentes impulsionando esses projetos educativos, a partir das avaliaçóes de desempenho institucional que os governos têm implantado na administração pública. Segundo Eilean Hooper-Greenhill, pesquisadora da Universidade de Leicester (UK), "Museus, arquivos e bibliotecas na Inglaterra têm operado em um clima político guiado por resultados, como outras instituiçôes culturais internacionais. A necessidade de prestar contas e de demonstrar valor social tem levado a uma demanda pela mensuração do impacto e de resultados de aprendizagem [das ações educativas dessas instituiçôes.” (HOOPER- 
-GREENHILL 2004: 151). [Tradução da autora] Nesse texto a autora também descreve a ação do governo americano no controle dos projetos educativos de seus arquivos e museus, expondo como a verba para realização de projetos e eventos dos arquivos vincula-se à sua avaliação: os projetos de ação educativa aprovados devem estar alinhados com as diretrizes curriculares nacionais, e sua avaliação decidirá quais serão os projetos futuros.

Junto com a ênfase nas habilidades de aprendizagem e na afirmação da identidade e da memória, a inserção dos aprendizes na chamada sociedade do conhecimento, através do letramento digital, é outro objetivo apontado nas açóes educativas de arquivos on-line. Peter Burke (BURKE, 2004: 314) conta que, em 1996, o "grande dia simbólico" foi o que marcou a conexão dos telefones fixos das salas de aula das escolas da Califórnia à Internet. Clinton prometeu que todas as salas de aula dos EUA estariam conectadas à rede "no próximo século", e seu Secretário de Educação descreveu a Internet como "o quadro negro do futuro". Mais adiante, Burke adverte-nos para olharmos para a rede não como fantasia incorpórea, mas para suas bases fincadas no mundo material: o ciberespaço tem sua economia, suas açóes nas bolsas, seus atores políticos, suas agências de planejamento e regulamentação. Pertence ao mundo dos homens, com seus conflitos e seu peso.

Como os arquivos têm colocado atividades de ensino com o uso da tecnologia digital? As formas variam. Com a emergência das novas possibilidades tecnológicas os arquivos têm-se proposto a criar redes e portais conjuntos - arquivos em rede; têm experimentado o uso de mídias convergentes - vídeo, som, animação, jogos de computador, mídias sociais, tecnologia de digitalização e tratamento de imagem, ampliando e atualizando as práticas educativas anteriores ao uso das TICs nos arquivos: exposiçóes, kits didáticos, arquivo simulado, jogos lógicos, ente outros (BELLOTTO, 1991: 147-163).

No campo da publicação de documentos com objetivos educativos, deparamo-nos com outro argumento bastante difundido, que é preciso conhecer melhor, que é o "do acesso" à informação informatizada e à rede, ligado ao letramento digital para a educaçáo dos jovens. Como nos alertam André Favacho e Daniel Mill (FAVACHO e MILL, 2007: 200), a figura do jovem com futuro alegre, com dinheiro e bem informado é um tipo de enunciado produzido pelo discurso tecnológico contemporâneo que lida com um imaginário profundo, que é a alegria/felicidade, ao mesmo tempo em que lida com o grande sagrado da modernidade (capital/dinheiro), bem como com o fetiche do saber/informação. São, portanto, três elementos (felicidade, dinheiro e informação) que aparentemente estão isolados, mas no fundo articulam-se para a criação de um discurso com forte poder de sedução. Sedução esta que se dá via promessa de um futuro melhor, que busca na complexidade destes três elementos uma possível "substância ética" da contemporaneidade, isto é, um valor de verdade. Em outras palavras, vivemos um discurso tecnológico ou, como preferimos denominar, um discurso do acesso.

Se, com base nas tecnologias digitais, a informação deixou de ser um meio para atingir um valor econômico e social, e passou a ser ela mesma o próprio valor, nesse universo permeado por tecnologias da informação e comunicação, as organizações dominantes, numa dada rede, são aquelas que controlam as informaçôes, definem os canais de comunicação, transferem recursos e estabelecem padróes de ação para outras unidades constitutivas da rede. Os pesquisadores 
concluem que, dessa maneira, todo o corpo social estaria plenamente envolvido com a sedução do discurso do acesso, justificado na estratégia do mercado e na vontade de todos em fazer parte da sociedade em que habitam: o discurso tecnológico ou do acesso imputa o sentido de felicidade na informação. Assim, a informação deixa de ser o meio para atingir a felicidade e passa a ser ela mesma a própria felicidade. $\mathrm{O}$ acesso à felicidade torna-se o acesso à informação.

Se nos voltarmos, com essa leitura do discurso tecnológico em mente, para as demandas da economia da memória, podemos imaginar sua combinaçáo poderosa de desejo e atração, que tem colaborado, também, para ampliar o campo de ação educativa dos arquivos e impulsionar a criação de narrativas históricas on-line, justificando, talvez, as grandes somas de dinheiro investidas nesses projetos. Pois para serem bem sucedidas essas empreitadas custam muito, muito dinheiro, não só em sua criação, como em sua sobrevivência à obsolescência programada das mídias e dos discursos. A demanda crescente pelo consumo do "passado guardado nos arquivos" parece tornar-se imperativa, e parece ter aportado nos arquivos, atualizada em desejo de "tudo digitalizar", de "tudo guardar" e de "tudo publicar on-line" e de "dar acesso" a "todo o passado", sua "história" e "memória".

Mas como tudo nessa nova "economia da memória" passa rapidamente, e ameaça tornar-se obsoleto mal é criado, os arquivos precisam medir os esforços e planejar os passos para responder com sensatez e responsabilidade a essa exposição midiática e às suas demandas. Os arquivos são instituiçôes organizadas para a longa duração. Com seus corredores inóspitos e hors d'usage (fora de uso), como nos lembra Pierre Nora. E dessa imagem de ligação com "o que dura" é que vem, talvez, sua atração, para quem se vê perdido nesse tempo que tudo consome.

Enfim, embora seu potencial de informação e seu poder de atração sejam enormes, nesse terreno da digitalização e do acesso eletrônico aos documentos de arquivo tudo está sendo construído. Maurice Tardif (TARDIF, 2005) escreve sobre as relaçóes entre a aprendizagem de competências e habilidades para a sociedade do conhecimento, entre elas o uso das TICs no ensino, lembrando que as tecnologias são construçóes que representam, através de mecanismos e recursos tangíveis, projetos humanos, práticos e simbólicos. Insere, assim, a discussão das TICs em seu lugar socio-político, lembrando-nos que em certo sentido, as tecnologias de informação e comunicação são projeções simbólicas e cognitivas tornadas reais, práxis concretizadas em um sistema de objetos materiais, funcionais e operacionais.

E porque derivam de pensamentos e práxis humanos, as tecnologias estão sempre inseridas em redes de trabalho, agrupamentos técnicos, sistemas de instrumentos e práticas. Então, sua forma, estrutura, uso e função vêm desses projetos práticos e simbólicos, discursos que elas continuam a carregar em seus diversos usos e funçóes. Cabe-nos refletir sobre esses projetos e propor açóes que avancem na compreensão da produção de conhecimento histórico escolar nos arquivos.

Em resumo, nessa investigação procurei refletir sobre como os arquivos têm buscado colocar-se em suas experiências educativas, em especial no acesso virtual pela web, destacando algumas questóes que considero fundamentais, como a da consideraçáo da especificidade dos documentos de arquivo, e que ainda estão em aberto, como campo de reflexão e de ação, nesses novos espaços de educação patrimonial. Como horizonte de pesquisa, busco formas de se criar 
projetos de educação com o uso de documentos de arquivo que se abram para as dimensôes da experiência, como a percebem E. P. Thompson (THOMPSON, 2010) e Walter Benjamin (2007), em contraposição à monumentalização dos documentos que encontramos em tantos projetos educativos on-line hoje.

\section{REFERÊNCIAS BIBLIOGRÁFICAS}

BENJAMIN, Walter. Passagens. Belo Horizonte: Editora da UFMG, 2007.

BRASIL. Ministério da Educação. Secretaria de Educação Média e Tecnológica. Parâmetros Curriculares Nacionais. Ensino Médio: Ciências Humanas e Suas Tecnologias. Brasília: MEC, 1999. lia: MEC, 1997.

Parâmetros Curriculares Nacionais: História, Geografia. Brasí-

BellotTO, H. L. Arquivos Permanentes: Tratamento Documental. São Paulo: T. A. Queiroz, 1991.

BRIGGS, Asa, PETER, Burke. Uma História Social da Midia: de Gutenberg à Internet. Rio de Janeiro: Jorge Zahar, 2004.

CAMARGO, Ana Maria de Almeida. "Os arquivos da polícia política como fonte”. In: Registro, V.1, No 1, Julho 2002 - Indaiatuba: Fundação Pró- Memória de Indaiatuba, 2002.

CASTELLS, Manuel. A sociedade em Rede. São Paulo: Paz e Terra, 1999. v. 1.

CATE, Ann ten. "Outreach in a small archives: a case history" In: Archivaria 28 (Summer 1989): 28-35.

CHOAY, Françoise. A Alegoria do Patrimônio. São Paulo: UNESP, 2001.

FAVACHO, André; MILL, Daniel. "Funçôes do discurso tecnológico na sociedade contemporânea”. In: Pro-Posiçôes, v. 18, n. 2 (53). Campinas: Unicamp, 2007.

GALZERANI, Maria Carolina Bovério. "Memória, história e tempo: perspectivas teórico-metodológicas para a pesquisa em ensino de História”. In: $\mathrm{Ca}$ dernos do CEOM - Memória, História e Educação, v. 28, p. 15-30. Chapecó: UNOESC, 2008.

HOOPER-GREENHILL, Eilean. "Measuring learning outcomes in museums, archives and libraries: the learning impact research project (LIRP)". In: International Journal of Heritage Studies Vol. 10, No. 2, May 2004, pp. 151-174.

HUYSSEN, Andréas. Seduzidos pela Memória. Arquitetura, Monumentos, Mídia. RJ: Aeroplano, 2000.

KNAUSS, Paulo. "História de coleção e história de exposição". In: História Representada: O Dilema dos Museus. Rio de Janeiro: Museu Histórico Nacional, 2003, v. 1, p. 127-134.

LE GOFF, Jacques. “Documento/monumento”. In: Memória - História. Enciclopédia Einaudi, v.1. Lisboa: Imprensa Nacional, 1984.

MATTOZZI, Ivo. "Archivi simulati e didattica della ricerca storica: per un sistema formativo integrato tra archivi e scuole". In: Archivi Locali e Insegnamenti Storici, Archivio Storico Comune di Modena, Modena, 2001, pp. 11-23.

NORA, Pierre. "Missions et enjeux des archives dans les sociétés contemporaines". In : Comma, 2003, 2/3, p 47-49. Paris: International Council of Archives, 2003.

SAND, Viki. "History resource units from the Minnesota Historical Society". In: American Archivist, abril de 1978, v 41, n.2.

SÃO PAULO (Estado). Secretaria de Estado da Educação. Proposta Curricular 
Para o Ensino de História $1^{\circ}$ grau. Sáo. Paulo: SEE: CENP, 1986.

TARDIF, Maurice. "Communication technology and pedagogical power". In: Essays in Education, v.14, 2005, University Of South Carolina. Disponível em: http://www.usca.edu/essays/vol142005/tardif.pdf. Acesso em: 15 de abril de 2012.

THOMPSON, Edward Palmer. Costumes em Comum: Estudos Sobre a Cultura

Popular Tradicional. São Paulo: Companhia das Letras, 2010. 